\title{
Effects of intraoperative single bolus fentanyl administration and remifentanil infusion on postoperative nausea and vomiting
}

\author{
Hyungsun Lim, A Ram Doo, Ji-Seon Son, Jin-Wan Kim, Ki-Jae Lee, \\ Dong-Chan Kim, and Seonghoon Ko \\ Department of Anesthesiology and Pain Medicine, Chonbuk National University Medical School and Hospital, \\ Jeonju, Korea
}

\begin{abstract}
Background: Although the use of postoperative opioids is a well-known risk factor for postoperative nausea and vomiting (PONV), few studies have been performed on the effects of intraoperative opioids on PONV. We examined the effects of a single bolus administration of fentanyl during anesthesia induction and the intraoperative infusion of remifentanil on PONV.

Methods: Two hundred and fifty women, aged 20 to 65 years and scheduled for thyroidectomy, were allocated to a control group (Group C), a single bolus administration of fentanyl $2 \mu \mathrm{g} / \mathrm{kg}$ during anesthesia induction (Group F), or $2 \mathrm{ng} /$ $\mathrm{ml}$ of effect-site concentration-controlled intraoperative infusion of remifentanil (Group R) groups. Anesthesia was maintained with sevoflurane and $50 \% \mathrm{~N}_{2} \mathrm{O}$. The incidence and severity of PONV and use of rescue antiemetics were recorded at 2,6 , and $24 \mathrm{~h}$ postoperatively.

Results: Group F showed higher incidences of nausea (60/82, 73\% vs. 38/77, 49\%; P = 0.008), vomiting (40/82, $49 \%$ vs. 23/77 30\%; P = 0.041) and the use of rescue antiemetics (47/82, 57\% vs. 29/77, 38\%; P = 0.044) compared with Group C at postoperative $24 \mathrm{~h}$. However, there were no significant differences in the incidence of PONV between Groups C and R. The overall incidences of PONV for postoperative $24 \mathrm{~h}$ were $49 \%, 73 \%$, and $59 \%$ in Groups C, F, and R, respectively (P = 0.008).

Conclusions: A single bolus administration of fentanyl $2 \mu \mathrm{g} / \mathrm{kg}$ during anesthesia induction increases the incidence of PONV, but intraoperative remifentanil infusion with $2 \mathrm{ng} / \mathrm{ml}$ effect-site concentration did not affect the incidence of PONV.
\end{abstract}

Key Words: Fentanyl, Intraoperative period, Postoperative nausea and vomiting, Remifentanil.

Corresponding author: Seonghoon Ko, M.D., Ph.D.

Department of Anesthesiology and Pain Medicine, Chonbuk National University Medical School and Hospital, 20 Geonji-ro, Deokjin-gu, Jeonju 54907, Korea

Tel: 82-63-250-1979, Fax: 82-63-250-1240

E-mail: shko@jbnu.ac.kr

Received: June 29, 2015.

Revised: 1st, August 26, 2015; 2nd, October 19, 2015; 3rd, October 26, 2015. Accepted: October 27, 2015.

Korean J Anesthesiol 2016 February 69(1): 51-56 http://dx.doi.org/10.4097/kjae.2016.69.1.51

\section{Introduction}

Postoperative nausea and vomiting (PONV) is a distressing adverse effect that may result in postoperative complications including bleeding, wound dehiscence, aspiration pneumonitis, and fluid and electrolyte imbalances [1]. The incidence of PONV ranges from $22 \%-52 \%$ despite advance in anesthetics and anesthesia techniques [2-4]. The etiology of PONV remains unclear, but the contributing factors are complex including gender, smoking, a history of motion sickness or previous PONV, anesthetic technique, type of surgery, and the use of opioids

(c) This is an open-access article distributed under the terms of the Creative Commons Attribution Non-Commercial License (http://creativecommons.org/ licenses/by-nc/4.0/), which permits unrestricted non-commercial use, distribution, and reproduction in any medium, provided the original work is properly cited. 
[5]. Among the risk factors of PONV, the use of postoperative opioids is one of the four major risk factors in the simplified risk scoring system devised by Apfel et al. [6]. The use of postoperative opioids strongly affects the incidence of PONV in a doserelated manner [7]. In the Society for Ambulatory Anesthesia Consensus Guidelines for the management of PONV, one of the strategies for reducing the baseline risk factors of PONV is the minimization of intraoperative and postoperative opioid use [5].

In addition to postoperative analgesia, opioids have often been used to reduce the hemodynamic response to laryngoscopy and tracheal intubation or to blunt surgical stimulation during anesthesia management. Most anesthesiologists prefer shortacting opioids such as remifentanil or fentanyl rather than longacting opioids for this purpose because long-acting opioids may cause postoperative adverse effects including respiratory depression, PONV, urinary retention, and pruritus. Therefore, smalldose fentanyl or remifentanil infusion is commonly employed to reduce the hemodynamic response to tracheal intubation during anesthesia induction or to ablate responsiveness to noxious intraoperative stimuli as a balanced anesthesia concept [8-11].

Although a number of clinical reports have identified the use of postoperative opioids as one of the major risk factors of PONV, few studies have been performed that focus on the effects of intraoperative opioid use on the incidence and severity of PONV [12-14]. Furthermore, studies regarding the effects of a single bolus administration of fentanyl during anesthesia induction or the intraoperative infusion of remifentanil on PONV are rare. We conducted a prospective, randomized, double-blinded study to compare the incidence and severity of PONV in female patients undergoing thyroidectomy who received a single bolus intravenous administration of fentanyl during anesthesia induction or infusion of remifentanil during the operation.

\section{Materials and Methods}

This study was approved by the Institutional Review Board of author's institution and registered with the WHO International Clinical Trials Registry Platform (KCT0001126). After obtaining written informed consent, 250 female patients, aged 20-65 years and American Society of Anesthesiologists physical status I or II, undergoing thyroidectomy were enrolled in this prospective study. Patients with a history of motion sickness or PONV, diabetes mellitus or gastrointestinal disease, and those who were smokers, menstruating, or who had taken antiemetics or steroids within $72 \mathrm{~h}$ prior to surgery were excluded from the study. Because the four major risk factors are female gender, non-smoking, use of postoperative opioids, and prior history of motion sickness or PONV according to Apfel's simplified risk scoring system [6], the enrolled patients in this study had two risk factors of PONV. Patients were allocated randomly to one of three groups: the control group (Group C), $2 \mu \mathrm{g} / \mathrm{kg}$ of a single bolus administration of fentanyl during anesthesia induction (Group F), or $2 \mathrm{ng} / \mathrm{ml}$ of effect-site concentration of remifentanil with a target-controlled infusion (Group R) using computergenerated random numbers.

The anesthetic regimen was standardized for all patients. No patient received preanesthetic medication. All patients were monitored by electrocardiography, noninvasive blood pressure, temperature, pulse oximetry, and capnography. Anesthesia was induced with thiopental sodium $4-6 \mathrm{mg} / \mathrm{kg}$ and rocuronium $1.0 \mathrm{mg} / \mathrm{kg}$. Anesthesia was maintained with sevoflurane and $50 \%$ nitrous oxide in oxygen. End-tidal carbon dioxide partial pressure was maintained at 30-35 $\mathrm{mmHg}$. The arterial blood pressure was kept within $20 \%$ of the preanesthetic values. Sevoflurane was administered to maintain an end-tidal sevoflurane concentration of $0.5 \%-3.0 \%$ according to blood pressure. Endtidal sevoflurane concentration was recorded every $5 \mathrm{~min}$. A balanced salt solution was infused at a rate of 4 to $6 \mathrm{ml} / \mathrm{kg} / \mathrm{h}$ during surgery except in cases of overt intraoperative blood loss. At the completion of surgery, inhalational anesthetics and remifentanil infusion were stopped. Residual neuromuscular blockade was antagonized with glycopyrrolate and pyridostigmine, and the trachea was extubated. Patients were administered $30 \mathrm{mg}$ of ketorolac intravenously upon closure of the skin. Although the anesthesiologists in the operating room were not blinded to the group assignment, the data-collecting anesthesiologists in the postanesthesia care unit (PACU) and the ward, who did not perform the anesthetic management in the operating room, were blinded to the group allocations.

To assess nausea and vomiting, patients were monitored for $2 \mathrm{~h}$ in the PACU and interviewed in the ward at postoperative 6 and $24 \mathrm{~h}$. PONV during periods 0 to 2 h, 2 to $6 \mathrm{~h}$, and 6 to 24 $\mathrm{h}$ after anesthesia was evaluated by an anesthesiologist blinded to the study groups or by the spontaneous complaints of the patients. Nausea was defined as a subjectively unpleasant sensation associated with an awareness of the urge to vomit, and vomiting was defined as the forceful expulsion of gastric contents from the mouth. Rescue antiemetics were given immediately when the patients showed vomiting or required rescue medications. The first-line rescue antiemetic was ondansetron $4 \mathrm{mg}$, which was followed by metoclopramide $10 \mathrm{mg}$ as a second-line treatment.

Any episode of nausea or vomiting during the $24 \mathrm{~h}$ period following surgery was considered an occurrence of PONV. Nausea severity was recorded using a Visual Analog Scale (nauseaVAS; where $0 \mathrm{~cm}=$ no nausea and $10 \mathrm{~cm}$ = worst possible nausea) at postoperative 2, 6, and $24 \mathrm{~h}$. Vomiting was assessed by the number of vomiting occurrences. The incidence and severity of PONV and administration of rescue antiemetics were recorded. In addition to 2,6 , and $24 \mathrm{~h}$, PONV was noted any time a 
patient complained of nausea or vomiting in the PACU or ward. The amount and time of administration of rescue antiemetics were recorded. Postoperative pain was evaluated using a VAS (pain-VAS; where $0 \mathrm{~cm}=$ no pain and $10 \mathrm{~cm}=$ worst possible pain), simultaneously. Patients received intravenous ketorolac as a rescue analgesic when required.

\section{Statistics}

The sample size was predetermined by the Proportions Sample Size using SigmaPlot 12.0 (Systat Software Inc. San Jose, USA) based on the assumption that the incidence of PONV, which was regarded as the primary endpoint, would be $35 \%$ in Group C and 60\% in Groups F and R. It was ascertained that 70 patients were required in each group with a significance level of $0.05(\alpha=0.05)$ and a power of $80 \%(\beta=0.20)$. To allow for attrition, the total sample size was enlarged to 250 .

Statistical analysis was performed with SigmaPlot 12.0. Continuous variables were analyzed with one-way analysis of variance. The incidence of PONV and use of rescue antiemetics were analyzed using the Chi-square test. The Holm-Sidak method and the Bonferroni correction were used for multiple comparisons after the ANOVA test and the Chi-square test, respectively. All data are expressed as mean \pm standard deviation, or patient number and percentage. A $\mathrm{P}$ value of less than 0.05 was considered statistically significant.

\section{Results}

Two hundred and thirty-three patients completed the study, and the subject flow diagram is shown in Fig. 1. The three groups were comparable for patient characteristics, anesthesia time, and volume of fluids administered (Table 1). The doses of intraoperative opioids were fentanyl $120 \pm 17 \mu \mathrm{g}$ and remifentanil $283 \pm 98 \mu \mathrm{g}$ in patient Groups $\mathrm{F}$ and $\mathrm{R}$, respectively.

The incidence of PONV and use of rescue antiemetics are listed in Table 2. Patients who received fentanyl during anesthesia induction (Group F) showed higher incidences of nausea (adjusted $\mathrm{P}=0.013$ ) and use of rescue antiemetics (adjusted $\mathrm{P}$ $=0.003$ ) compared with Group $\mathrm{C}$ at $0-2 \mathrm{~h}$. However, there were no significant differences in the incidences of PONV and use of rescue antiemetics between Groups $\mathrm{C}$ and $\mathrm{R}$ during the first postoperative $24 \mathrm{~h}$. The overall incidences of PONV were 55, 73, and $59 \%$ in Groups $\mathrm{C}, \mathrm{F}$, and $\mathrm{R}$, respectively $(\mathrm{P}=0.008)$. There was a significant difference between Groups $\mathrm{C}$ and $\mathrm{F}$ (adjusted $\mathrm{P}=0.003$ ), but no difference between groups $\mathrm{C}$ and $\mathrm{R}$ (adjusted $\mathrm{P}=0.279$ ) for $24 \mathrm{~h}$. No significant differences were shown in the PONV-VAS for those patients who had PONV (Table 3). There were no differences in the pain-VAS among the three groups in each time period (Table 4). The end-tidal sevoflurane concentrations during the operation were lowest in Group R (Fig. 2). No patients showed opioid-related complications, such as respiratory depression, urinary retention, or pruritus in Groups F and R.

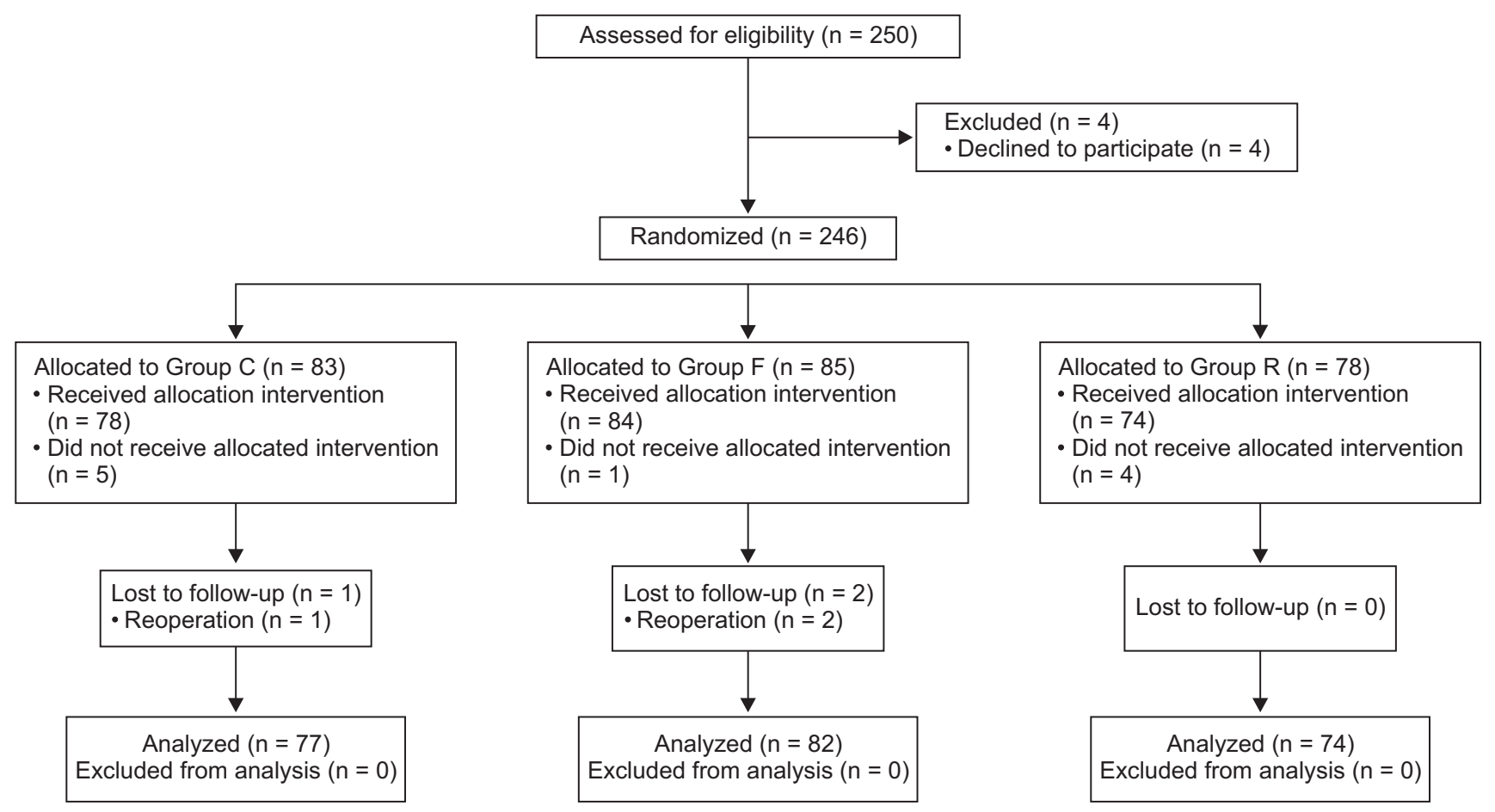

Fig. 1. Subject flow diagram. 
Table 1. Patients Characteristics

\begin{tabular}{|c|c|c|c|c|}
\hline & Group C & Group F & Group R & $P$ values \\
\hline Number of patient & 77 & 82 & 74 & \\
\hline Age $(y r)$ & $46.9 \pm 9.9$ & $47.0 \pm 11.5$ & $47.3 \pm 9.8$ & 0.977 \\
\hline Height $(\mathrm{cm})$ & $157.1 \pm 5.6$ & $157.4 \pm 5.4$ & $157.5 \pm 5.5$ & 0.892 \\
\hline Weight $(\mathrm{kg})$ & $59.8 \pm 9.8$ & $60.1 \pm 8.4$ & $59.4 \pm 7.5$ & 0.880 \\
\hline Anesthesia time (min) & $106.9 \pm 29.4$ & $105.7 \pm 25.9$ & $100.6 \pm 28.4$ & 0.338 \\
\hline ASA PS (I/II) & $60 / 17$ & $62 / 20$ & $61 / 13$ & 0.577 \\
\hline Fluid (ml/h/kg) & $4.7 \pm 2.2$ & $4.5 \pm 1.7$ & $4.7 \pm 1.9$ & 0.765 \\
\hline
\end{tabular}

Values are mean \pm SD. ASA PS: American Society of Anesthesiologists Physical Status.

Table 2. Incidences of Postoperative Nausea and Vomiting and Use of Rescue Antiemetics

\begin{tabular}{|c|c|c|c|c|c|}
\hline & & $\begin{array}{c}\text { Group C } \\
(\mathrm{n}=77)\end{array}$ & $\begin{array}{l}\text { Group F } \\
(\mathrm{n}=82)\end{array}$ & $\begin{array}{l}\text { Group R } \\
(\mathrm{n}=74)\end{array}$ & $P$ value \\
\hline \multirow[t]{3}{*}{$0-2 \mathrm{~h}$} & Nausea & $28(36 \%)$ & $47(57 \%)^{*}$ & $37(50 \%)$ & 0.028 \\
\hline & Vomiting & $16(21 \%)$ & $27(33 \%)$ & $21(28 \%)$ & 0.225 \\
\hline & Rescue medications & $20(26 \%)$ & $41(50 \%)^{*}$ & $31(42 \%)$ & 0.007 \\
\hline \multirow[t]{3}{*}{$2-6 \mathrm{~h}$} & Nausea & $28(36 \%)$ & $41(50 \%)$ & $22(30 \%)$ & 0.029 \\
\hline & Vomiting & $10(13 \%)$ & $22(27 \%)$ & $8(11 \%)$ & 0.004 \\
\hline & Rescue medications & $9(12 \%)$ & $14(17 \%)$ & $6(8 \%)$ & 0.231 \\
\hline \multirow[t]{3}{*}{$6-24 \mathrm{~h}$} & Nausea & $13(17 \%)$ & $20(24 \%)$ & $10(14 \%)$ & 0.197 \\
\hline & Vomiting & $4(5 \%)$ & $8(10 \%)$ & $4(5 \%)$ & 0.437 \\
\hline & Rescue medications & $8(10 \%)$ & $6(7 \%)$ & $2(3 \%)$ & 0.171 \\
\hline \multirow[t]{3}{*}{$0-24 \mathrm{~h}$} & Nausea & $38(50 \%)$ & $60(73 \%)^{*}$ & $44(59 \%)$ & 0.008 \\
\hline & Vomiting & $22(29 \%)$ & $40(49 \%)^{*}$ & $29(39 \%)$ & 0.041 \\
\hline & Rescue medications & $28(36 \%)$ & $47(57 \%)^{*}$ & $34(46 \%)$ & 0.044 \\
\hline
\end{tabular}

*Adjusted $\mathrm{P}<0.017$ compared to Group C.

Table 3. Severity of Postoperative Nausea and Vomiting (PONV)

\begin{tabular}{llllll}
\hline & & Group C & Group F & Group R & P values \\
\hline \multirow{2}{*}{ PONV-VAS } & $2 \mathrm{~h}$ & $4.0 \pm 2.0$ & $5.2 \pm 2.7$ & $5.3 \pm 2.8$ & 0.214 \\
& $6 \mathrm{~h}$ & $4.0 \pm 2.9$ & $4.1 \pm 2.6$ & $3.1 \pm 2.9$ & 0.529 \\
& $24 \mathrm{~h}$ & $4.5 \pm 2.3$ & $3.8 \pm 2.5$ & $2.3 \pm 2.0$ & 0.186 \\
\hline
\end{tabular}

Values are mean \pm SD. VAS: visual analog scale.

Table 4. Pain Scores

\begin{tabular}{cllllc}
\hline & Group C & Group F & Group R & P values \\
\hline \multirow{2}{*}{ Pain-VAS } & $0-2 \mathrm{~h}$ & $3.3 \pm 1.5$ & $3.8 \pm 1.9$ & $3.8 \pm 2.0$ & 0.152 \\
& $2-6 \mathrm{~h}$ & $2.5 \pm 1.7$ & $2.7 \pm 2.0$ & $2.7 \pm 2.0$ & 0.726 \\
& $6-24 \mathrm{~h}$ & $2.1 \pm 1.7$ & $2.2 \pm 1.9$ & $1.9 \pm 1.7$ & 0.521 \\
\hline
\end{tabular}

Values are mean \pm SD. VAS: visual analog scale.

\section{Discussion}

This study examined the emetic effects of a single bolus fentanyl administration during anesthesia induction and intraoperative continuous infusion of remifentanil on PONV. In the current study, there were no significant differences in the incidence and severity of PONV and requirement of rescue antiemetics in patients who received intraoperative remifentanil infusion compared with control patients. The overall incidences of PONV were 55\% in the control group and 59\% in the remifentanil group. These incidences were similar to those of previous studies of PONV after thyroidectomy [15]. However, patients who received $2 \mu \mathrm{g} / \mathrm{kg}$ of fentanyl during anesthesia induction showed higher incidences of PONV compared with control patients. 


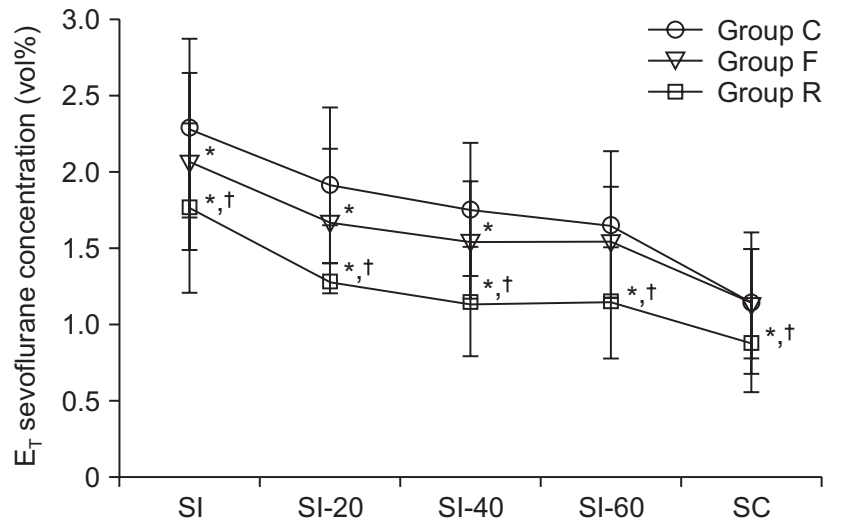

Fig. 2. The end-tidal $\left(E_{T}\right)$ sevoflurane concentrations were lower in Groups $\mathrm{F}$ and $\mathrm{R}$ compared with Group $\mathrm{C}$ from skin incision to $40 \mathrm{~min}$ after skin incision. In Group R, end-tidal sevoflurane concentrations were lower throughout the operation compared with Groups $\mathrm{C}$ and F. $* \mathrm{P}<$ 0.05 compared with Group C. ${ }^{\dagger} \mathrm{P}<0.05$ compared with Group F. SI: Skin incision, SI-20: $20 \mathrm{~min}$ after skin incision, SI-40: $40 \mathrm{~min}$ after skin incision. SC: Skin closure.

Because opioids commonly cause nausea and vomiting, the use of opioids is one of the major risk factors of PONV. Therefore, anesthesia strategies to avoid or reduce administration of opioids are effective means of reducing the risk for PONV. In fact, consensus guidelines for the management of PONV recommend the minimization of intraoperative and postoperative opioid use for the management of PONV [5]. Although a few studies have reported the effects of intraoperative opioid use on the incidence of PONV, the results were controversial [16-18]. These previous studies had small numbers of subjects, and the opioids were used for postoperative analgesia. These may affect the interpretation of the results. Therefore, large prospective study that excludes the effect of postoperative opioids is required to demonstrate the effect of intraoperative opioids on PONV.

A single bolus administration of small-dose fentanyl has been used to reduce the hemodynamic response to tracheal intubation 3-5 min before intubation [9]. Fentanyl concentration at the effect site peaks $3.6 \mathrm{~min}$ after the bolus injection, which is $17 \%$ of the initial plasma concentration $[9,19]$. At 120 min after the bolus injection, the mean anesthesia time of the current study, the relative effect-site fentanyl concentration is approximately $10 \%$ of the peak effect-site concentration [19]. Because remifentanil is hydrolyzed by nonspecific esterase and has a very short context-sensitive half-time, the time required for a $50 \%$ reduction in the effect-site concentration of remifentanil was very short (3.65 $\mathrm{min}$ ) regardless infusion duration [20]. Although the effect-site concentrations of fentanyl and remifentanil were not compared at the early postoperative period, the differences of PONV incidence between Groups F and R may have been influenced by effect-site concentrations. Although there were no differences in PONV among the volatile anesthetics isoflurane, sevoflurane, and desflurane, volatile anesthetics are known to have emetogenic effects $[21,22]$. The vomiting incidence of volatile anesthetics was different from propofol in the early postoperative period and the difference is dose-related [23]. Sevoflurane consumption was less in Group R than Group F during operation. The lower use of sevoflurane in Group $\mathrm{R}$ may have influenced the incidence of PONV compared with Group F. However, the PONV incidence was higher in Group F than Group C, although the sevoflurane consumption was less in Group F. This result demonstrates that the residual effect of fentanyl influenced PONV more than emetogenic effect of sevoflurane. Intraoperative hypotension can affect the incidence of PONV. Because blood pressure was kept within $20 \%$ of the preanesthetic values by adjusting the sevoflurane administration, intraoperative blood pressure may not have affected the incidence of PONV in this study.

In this study, the contributing factors of PONV were controlled among the groups including patient demographic characteristics, surgical procedure, history of motion sickness and/or previous PONV, smoking, inhalational anesthetics, and postoperative use of analgesics. By eliminating the factors that affect PONV, the results of this study could therefore be attributed to the study setting. To exclude the effect of postoperative opioid use on PONV, intravenous ketorolac without opioids was administered for postoperative analgesia. Although inadequate analgesia was concerned, the pain score was maintained at less than 4.

Patients undergoing thyroidectomy have a remarkably high incidence of PONV when no prophylactic antiemetic is given [15]. The cause of the high PONV incidence after thyroidectomy is not known, but it may be related to several factors, including the age and sex of patients and vagal stimulation through surgical handling of the neck. Several studies have demonstrated the preventive effects of propofol on PONV compared with inhalational anesthetics [4,23-25]. In patients undergoing thyroidectomy, avoiding volatile anesthetics and nitrous oxide and using propofol for the induction and maintenance of anesthesia can considered for anesthesia management to reduce PONV.

There is a limitation of the current study. The subjects were not administered prophylactic antiemetics, which could be considered unethical. However, the patients were under close observation and received antiemetic rescue medications immediately when the patients showed vomiting or required rescue medications.

In conclusion, the current study demonstrated that a single bolus administration of $2 \mu \mathrm{g} / \mathrm{kg}$ of fentanyl during anesthesia induction increased the incidence of PONV, but intraoperative remifentanil infusion with $2 \mathrm{ng} / \mathrm{ml}$ of effect-site concentration did not affect the incidence and severity of PONV. 


\section{References}

1. Rose JB, Watcha MF. Postoperative nausea and vomiting in paediatric patients. Br J Anaesth 1999; 83: 104-17.

2. Koivuranta M, Läärä E, Snåre L, Alahuhta S. A survey of postoperative nausea and vomiting. Anaesthesia 1997; 52: 443-9.

3. Cohen MM, Duncan PG, DeBoer DP, Tweed WA. The postoperative interview: assessing risk factors for nausea and vomiting. Anesth Analg 1994; 78: 7-16.

4. Apfel CC, Korttila K, Abdalla M, Kerger H, Turan A, Vedder I, et al. A factorial trial of six interventions for the prevention of postoperative nausea and vomiting. N Engl J Med 2004; 350: 2441-51.

5. Gan TJ, Diemunsch P, Habib AS, Kovac A, Kranke P, Meyer TA, et al. Consensus guidelines for the management of postoperative nausea and vomiting. Anesth Analg 2014; 118: 85-113.

6. Apfel CC, Läärä E, Koivuranta M, Greim CA, Roewer N. A simplified risk score for predicting postoperative nausea and vomiting: conclusions from cross-validations between two centers. Anesthesiology 1999; 91: 693-700.

7. Roberts GW, Bekker TB, Carlsen HH, Moffatt CH, Slattery PJ, McClure AF. Postoperative nausea and vomiting are strongly influenced by postoperative opioid use in a dose-related manner. Anesth Analg 2005; 101: 1343-8.

8. Kautto UM, Heinonen J. Attenuation of circulatory response to laryngoscopy and tracheal intubation: a comparison of two methods of topical anaesthesia. Acta Anaesthesiol Scand 1982; 26: 599-602.

9. Ko SH, Kim DC, Han YJ, Song HS. Small-dose fentanyl: optimal time of injection for blunting the circulatory responses to tracheal intubation. Anesth Analg 1998; 86: 658-61.

10. Park SJ, Shim YH, Yoo JH, Nam SH, Lee JW. Low-dose remifentanil to modify hemodynamic responses to tracheal intubation: comparison in normotensive and untreated/treated hypertensive Korean patients. Korean J Anesthesiol 2012; 62: 135-41.

11. Sneyd JR, Whaley A, Dimpel HL, Andrews CJ. An open, randomized comparison of alfentanil, remifentanil and alfentanil followed by remifentanil in anaesthesia for craniotomy. Br J Anaesth 1998; 81: 361-4.

12. Shirakami G, Teratani Y, Segawa H, Matsuura S, Shichino T, Fukuda K. Omission of fentanyl during sevoflurane anesthesia decreases the incidences of postoperative nausea and vomiting and accelerates postanesthesia recovery in major breast cancer surgery. J Anesth 2006; 20: 188-95.

13. Cepeda MS, Gonzalez F, Granados V, Cuervo R, Carr DB. Incidence of nausea and vomiting in outpatients undergoing general anesthesia in relation to selection of intraoperative opioid. J Clin Anesth 1996; 8: 324-8.

14. Komatsu R, Turan AM, Orhan-Sungur M, McGuire J, Radke OC, Apfel CC. Remifentanil for general anaesthesia: a systematic review. Anaesthesia 2007; 62: 1266-80.

15. Metaxari M, Papaioannou A, Petrou A, Chatzimichali A, Pharmakalidou E, Askitopoulou H. Antiemetic prophylaxis in thyroid surgery: a randomized, double-blind comparison of three 5-HT3 agents. J Anesth 2011; 25: 356-62.

16. Rama-Maceiras P, Ferreira TA, Molins N, Sanduende Y, Bautista AP, Rey T. Less postoperative nausea and vomiting after propofol + remifentanil versus propofol + fentanyl anaesthesia during plastic surgery. Acta Anaesthesiol Scand 2005; 49: 305-11.

17. Jabalameli M, Rouholamin S, Gourtanian F. A comparison of the effects of fentanyl and remifentanil on nausea, vomiting, and pain after Cesarean section. Iran J Med Sci 2011; 36: 183-7.

18. Langevin S, Lessard MR, Trepanier CA, Baribault JP. Alfentanil causes less postoperative nausea and vomiting than equipotent doses of fentanyl or sufentanil in outpatients. Anesthesiology 1999; 91: 1666-73.

19. Shafer SL, Varvel JR. Pharmacokinetics, pharmacodynamics, and rational opioid selection. Anesthesiology 1991; 74: 53-63.

20. Westmoreland CL, Hoke JF, Sebel PS, Hug CC Jr, Muir KT. Pharmacokinetics of remifentanil (GI87084B) and its major metabolite (GI90291) in patients undergoing elective inpatient surgery. Anesthesiology 1993; 79: 893-903.

21. Gupta A, Stierer T, Zuckerman R, Sakima N, Parker SD, Fleisher LA. Comparison of recovery profile after ambulatory anesthesia with propofol, isoflurane, sevoflurane and desflurane: a systematic review. Anesth Analg 2004; 98: 632-41.

22. Wallenborn J, Rudolph C, Gelbrich G, Goerlich TM, Helm J, Olthoff D. The impact of isoflurane, desflurane, or sevoflurane on the frequency and severity of postoperative nausea and vomiting after lumbar disc surgery. J Clin Anesth 2007; 19: 180-5.

23. Apfel CC, Kranke P, Katz MH, Goepfert C, Papenfuss T, Rauch S, et al. Volatile anaesthetics may be the main cause of early but not delayed postoperative vomiting: a randomized controlled trial of factorial design. Br J Anaesth 2002; 88: 659-68.

24. Tramèr M, Moore A, McQuay H. Propofol anaesthesia and postoperative nausea and vomiting: quantitative systematic review of randomized controlled studies. Br J Anaesth 1997; 78: 247-55.

25. Sneyd JR, Carr A, Byrom WD, Bilski AJ. A meta-analysis of nausea and vomiting following maintenance of anaesthesia with propofol or inhalational agents. Eur J Anaesthesiol 1998; 15: 433-45. 